\title{
Health and Rights at the Margins: Human trafficking and HIV/AIDS amongst Jingpo ethnic communities in Ruili City, China
}

\author{
Elena Shih
}

\section{Abstract}

In 2007, China and Myanmar signed their first Bilateral Memorandum of Understanding on human trafficking. The two countries cemented this agreement with the unveiling of the first Border Liaison Office in Ruili City, located in China's southwestern Yunnan Province - one of the primary border crossing points between China and Myanmar. The government focus on human trafficking on this border intersects with decades of struggles to curb the border's porousness to drugs and HIV/AIDS. This paper is based on qualitative ethnographic participant observation and interviews with young Jingpo women living in Ruili City and investigates the risk of human trafficking as a by-product of cultural stigma associated with ethnic marginality, drugs, and HIV/AIDS. The case of Ruili warns us that the global shift towards regarding human trafficking as the single most perilous phenomenon of the current age obscures ongoing issues of vulnerability and cultural stigma for ethnic minority peoples globally. In lieu of state sponsored patrol and monitoring of the border, more attention must be paid to overlapping concerns of people living in border communities, including drug prevalence, disease, and ethnic marginalisation.

Key Words: Ruili City, Jingpo ethnicity, human trafficking, forced marriage, HIV/AIDS, cultural stigma

Please cite this article as: E Shih, 'Health and Rights at the Margins: Human trafficking and HIV/AIDS amongst Jingpo ethnic communities in Ruili City, China', Anti-Trafficking Review, issue 2, 2013, pp. 119-136, www.antitraffickingreview.org.

This is an open-access article distributed under the terms of the Creative Commons Attribution License (CC-BY). Under CC-BY license, the public is free to share, adapt, and make commercial use of the work. Users must always give proper attribution to the author(s) and the AntiTrafficking Review. 
On weekends, Ah Xian, a first year middle school student at Ruili City's Third Middle School, returns home to her village Banpai, 17 kilometers from Ruili City. She typically returns to an empty home: her twentyyear-old brother works as a security guard in a karaoke bar in Ruili City, her father died of AIDS-related illnesses last year, and her mother, who was sold into the family from Burma ${ }^{1}$ twenty years ago, now spends the majority of days in her own hometown just over the China-Myanmar border. Home looks equally barren for her cousins and next-door neighbours, aged 10 and 13, whose parents have been incarcerated for drug trafficking since 2005. Growing up without the presence of parents, the vacancy of the village is a reminder of limited alternatives for life after middle schoolobstacles that classify Ah Xian and her peers as at risk to human trafficking by recent transnational policy and rights agendas.

In Ruili City, on the China-Myanmar border, the flows of drugs, goods, and disease converge on the lives of indigenous and ethnic minority peoples living on both sides of the border. Ethnic minority communities in Ruili are both geographically and ethnically disenfranchised due to their isolation from China's economic hubs and state policies that offer structural benefits and systemic advantages for Han majority citizens. ${ }^{2}$ The high degree of mobility in this area brings Ruili into the forefront of the fight against human trafficking. Efforts to combat human trafficking in China focus on trafficking in 'women and children' for the exclusive purposes of forced marriage, forced prostitution and child kidnapping.

\footnotetext{
Throughout the paper I use 'Myanmar' to refer to the official documents and policies pertaining to the nation state. I use 'Burma', the name preferred by the Burmese democracy movement, in cases where respondents have used this language in English. Because almost all interviews were conducted exclusively in Chinese, the country was most commonly referred to by the single Chinese name: 缅甸 Miandian.

2 See: S Hyde, Eating Spring Rice: The cultural nature of AIDS in China's Southwest, University of Califronia Press, 2007; H Peters, 'Ethnicity along China's Southwestern Frontier', Journal of East Asian Archaeology, vol. 3, no. 1-2, 2001; R Deng, J Li, L Sringernyuang, and K Zhang, 'Drug Abuse, HIV/ AIDS and Stigmatisation in a Dai Community in Yunnan, China', Social Science \& Medicine, vol. 64, issue 8, 2007, pp.1560-1571; T Liu, 'Re-Constructing Cultural
} 
In Ruili City, these interventions are significant given recent media and humanitarian attention ${ }^{3}$ to cross-border forced marriage trafficking between Myanmar and China. These antitrafficking interventions have engaged the Chinese and Burmese governments through the signing of a Bilateral Memorandum of Understanding, the establishment of a Border Liaison Office with public security outposts on both sides of the border, and numerous joint meetings to discuss repatriation mechanisms for trafficked women and children. While the physical border has received focus as a critical site of government intervention, less attention has focussed on cases of internal forced marriage between ethnic minority communities in Yunnan's border regions and those living in other parts of China. ${ }^{4}$ Further, and central to the thesis of this paper, while trafficking is criminalised, very little attention is paid to the intersectional impact of illhealth, income inequality, ethnic marginalisation and a lack of community cohesion around anti-trafficking response.

Once labelled the lawless, yet undeveloped, Las Vegas of China, Ruili has represented a site of limited government regulation for its unbridled access to gambling, commercial sex, drugs, rare jade and other illegal commodities. In the past two decades, Chinese authorities have attempted to curb the lawless reputation of the area, systematically shutting down all of Ruili's casinos in 2005, vigilantly patrolling illegal trade in heroin,

Heritage and Imagining Wa Primitiveness in the China/Myanmar Borderlands', in Cultural Heritage Politics in China, Springer, New York, 2013, pp. 161-184; $\mathrm{J}$ Chio, 'Leave the Fields without Leaving the Countryside: Modernity and mobility in rural, ethnic China', Identities, vol. 18, issue 6, 2011, pp. 551575; B Gustafsson and L Shi, 'The Ethnic Minority Majority Income Gap in Rural China during Transition', Economic Development and Cultural Change, vol. 51, no. 4, 2003, pp. 805-822.

3 S Oo, 'Myanmar's Brides to China Top Human Trafficking List', The Myanmar Times, 7 January 2013, http://www.mmtimes.com/index.php/national-news/ 3705-brides-to-china-top-govt-human-trafficking-list.html; 'Media Field Study of Trafficking Myanmar Women to China', China Economics Weekly, February 2, English excerpt available in UNIAP News Digest, February 2010, pp. 3-4, www.notip.org.cn/UserImages/00001447.pdf.

4 In addition to the China-Myanmar border, the China-Vietnam border has also been an area of interest. 
and aggressively pursuing anti-HIV/AIDS campaigns through anti-drug use campaigns. ${ }^{5}$ The government's strategy of linking drug-use and HIV/AIDS is problematic because it conflates the illegality and punishment of drug-related crimes with the need for protection and services to those affected by HIV/AIDS. Such policing of drugs and disease has accelerated since 2009, when Ruili became the site of astronomical capital investment due to its strategic placement along the new superhighway that will connect China to Southeast Asia via Yunnan province. ${ }^{6}$

It is within this context of what the Chinese government labels as 'maintaining social stability' that efforts to control human trafficking might naturally appear fitting in Ruili City. However, given the complex landscape of issues that already plague the border area, this paper asks the question: What implications does the governance of human trafficking have for the ongoing criminalisation of drugs and disease along the China-Myanmar border? The article addresses this question primarily through investigating the links between the risks of human trafficking and HIV/AIDS amongst Jingpo ethnic communities living on the China-Myanmar border. It argues that the state's focus on policing marginality on the border through anti-HIV/AIDS and anti-trafficking interventions distracts attention from the problematic economic and political challenges ethnic minority communities face, thereby increasing systemic forms of inequality and marginalisation rather than decreasing the risk of human trafficking. Critical of how trafficking is being addressed in international and Chinese contexts, this paper details anti-trafficking efforts in Ruili, unpacking the intersectional issues that are not addressed in order to systemically and meaningfully impact trafficking.

5 On the 14-hour overnight bus journey from Ruili to Kunming, Yunnan's capital, all commuter buses are mandatorily stopped at four checkpoints along the way, where armed police officers and border police aggressively search bus cargo and passengers for drugs, detaining travellers for up to two hours at each checkpoint.

6 H Le Bail and A Tournier, 'From Kunming to Mandalay: The New "Burma Road"', Asie, Visions 25, March 2010.

$7 \mathrm{~J} \mathrm{Hu}$, Chinese Communist Party Central Committee on Building Socialism and Harmonious Society, and Other Important Issues by the Central Committee during the $6^{\text {th }}$ Plenum, October 2006. 


\section{Methodology}

The data for this paper is based on ethnographic research carried out through a local community arts project, the Border Statements Collective, which provides a no-cost public arts education as a tool of empowerment and education to ethnic minority youth living in Ruili villages. I have worked as an arts educator with the youth in this area since 2006, but most recently from 2011-2012, I interviewed women aged 16 and older to ask about their experiences with issues ranging from education, job, migration, and marriage opportunities to HIV/ AIDS and human trafficking. The sample population includes both women who were trafficked according to the UN Protocol definition and/or Chinese definition, though not identified as such, as well as those who could identify trafficking in their community. My research in this area was not conducted through government channels, nor through formal affiliation with a Chinese academic institution, but through a community art project that works principally through elementary schools in two primarily Dai and Jingpo villages near Ruili. These interviews were conducted with consenting family members of participating youth, but not the youth themselves. Pseudonyms are used for the village name and interview subjects in order to protect their privacy and anonymity.

\section{Jingpo Ethnic Communities}

The Jingpo are an ethnic minority group living across the borders of China, Myanmar, and India. The majority of Jingpo people in China live in Yunnan Province, and mainly in Dehong Prefecture. However, as this paper illustrates, growing numbers of internal marriage migration have brought Jingpo persons to China's northern and eastern provinces. In Myanmar, they are usually known as Kachin or Jinhpaw and in India as Singpho; while each of these distinct ethnonyms are nation-state specific, many cultural and linguistic similarities link the Jingpo communities living in different countries. The separation of the Jingpo, Kachin, Jinhpaw and Singpho thus illustrates how political borders shape ethnic politics when nation state borders 
often fracture ethnic community boundaries. ${ }^{8}$ Lack of legal citizenship, identity cards, access to information, and Mandarin language skills are some of the challenges that Jingpo communities in China face. ${ }^{9}$ The fact that the Jingpo ethnic community straddles nation-state borders complicates antitrafficking interventions that are heavily premised on border control.

\section{Border States and Anti-Trafficking}

The nature of borders and border policing highlight the enigmatic and unintended consequences of transnational attention to human trafficking, whose interventions exist, I argue, contradictorily between state control of its border sovereignty and human security across border regions. For instance, increased border security and policing that intend to restrict undocumented border crossings often force migrants to seek out more dangerous ways of migrating. ${ }^{10}$ Similarly, the emergence of state policies that relegate citizenship or residency rights to those deemed victims of human trafficking have been critiqued alongside the simultaneous crackdown on irregular migration. These critiques have argued that the humanitarian policies that anoint a select few human trafficking victims as deserving of state assistance create exclusionary pathways for migration and citizenship for non-victim categories-typically men, or victims of labour (as opposed to sexual) exploitation. ${ }^{11}$ Other scholars have traced the rise of

8 B Lintner, The Kachin: Lords of Burma's Northern Frontier, Teak House Publications, Bangkok, 1997; E Leach, Political Systems of Highland Burma: A study of Kachin social structure, vol. 44, Bloomsbury Academic, 1973.

$9 \quad M$ Liu and Y Hou, 'An Analysis of Western Chinese Minority Youths' Susceptibility to AIDS', Disasters, Culture, Politics: Chinese-Bulgarian Anthropological Contribution, vol. 1 no.1, 2009, pp. 207-221.

10 PAndreas, Border Games: Policing the US-Mexico divide, Cornell University Press, NY, 2001.

11 W Chapkis, 'Trafficking, Migration, and the Law: Protecting innocents, punishing immigrants', Gender \& Society, vol. 17, no. 6, 2003, pp. 923-937. For a discussion of state and international discourses around sexuality throughout China, see: P Suiming and H Yingying, "'Subjective Construction": Methodological revolution in sexuality research and potential development in Chinese context', Sociological Studies, 2007; E Jeffreys, Sex and Sexuality in China, Routledge, 2006. 
the human trafficking rescue industry alongside the size and privatisation of the deportation industry. ${ }^{12}$

The control of China's borders is of pivotal interest to the Chinese government, whose growing wealth and prominence in the region have made it a recent hub for migration from nearby countries in Southeast Asia, including the large-scale migration of both Vietnamese and Burmese seeking economic opportunities, and the specific recent migration of Burmese fleeing militarised conflict situations. ${ }^{13}$

\section{Anti-Trafficking in China}

The growing prevalence of cross-border and internal migration in China is increasingly understood within international and state-level frameworks of combating human trafficking. The global concern around human trafficking has provoked a transnational movement, formally spearheaded in 2000 by the United Nations Protocol to Prevent, Suppress and Punish Trafficking in Persons (Trafficking Protocol). Housed within a more comprehensive UN Convention against Transnational Organized Crime, the Trafficking Protocol is primarily a crime prevention framework, as opposed to a human rights or protection tool. When mobilised under an authoritarian regime such as China, the Protocol, strongly reinforces a punitive approach, which results in marginality amongst the people who are supposed to be helped.

12 L Agustin, Sex at the Margins: Migration, labour markets and the rescue industry, Zed Books, 2007. N De Genova and N Peutz (eds.), The Deportation Regime: Sovereignty, space, and the freedom of movement, Duke University Press, 2010.

13 The relative prosperity and safety of Ruili is likely to cause another issue as inequalities rise relative to neighbouring countries. Ruili is also an increasing point of entry for displaced persons from fighting in Burma's Kachin state. See: N Nadi 'Officials Reach out to Refugees following Fighting in Shan State', Democratic Voice of Burma, 16 May 2013. 
In 2009, China ratified this Protocol and in 2008, it signed its first five-year National Plan of Action to combat human trafficking. Despite its public acquiescence to international treaties and party to regional cooperation initiatives like the Coordinated Mekong Ministerial Initiative Against Trafficking (COMMIT) process, China has yet to adopt the international definition of human trafficking-acknowledging only the trafficking of women and children for the purposes of forced prostitution, forced marriage and child kidnapping. ${ }^{14}$ The trafficking of men and trafficking for purposes of labour exploitation are notably missing from the Chinese definition of trafficking. Finally, the relative newness of such legislative frameworks around human trafficking often do little to engage with existing policy around labour, migrant, and gender-based rights.

China has established its hub of counter-trafficking work through the Ministry of Public Security's Inter-Ministerial Office Against Trafficking (IMOAT), which, according to the mandates of the 'public security' department, focusses primarily on prosecuting and policing trafficking, rather than on victim protection or prevention. ${ }^{15}$ IMOAT claims considerable success, boasting that 24,000 women and children were rescued victims of human trafficking in 2011. ${ }^{16}$ However, reports of such 'rescues' only offer details about the prosecution and punishment of traffickers, rather than on victim protection or rehabilitation. Given the paucity of services for victim protection in China, recent efforts have focussed on improving victim services, including a national shelter improvement project co-funded

14 China's National Plan of Action on Combating Trafficking in Women and Children (2008-2012), http://www.no-trafficking.org/reports_docs/china/ china_npa_eng.pdf

15 United Nations, Protocol to Prevent, Suppress and Punish Trafficking in Persons, Especially Women and Children, Supplementing the U.N. Convention against Transnational Organized Crime, U.N. Doc. A/55/383; China's National Plan of Action, op. cit.; Ministry of Public Security Inter Minsterial Office Against Trafficking in Women and Children, http://www.mps.gov.cn/n16/n983040/ n1294479/index.html.

16 'Chinese Police Free 24,000 Abducted Women and Children', BBC News Asia, 11 March 2012, http://www.bbc.co.uk/news/world-asia-17330203. 
by UNIAP and the Ministry of Civil Affairs. However, merely 'improving' shelters still relegates trafficking victim serviceprovision through existing state structures such as the government shelters, which have a punitive history as the laststop for a range of people including those who are homeless, mentally ill, and victims of domestic violence. Research on the experiences of victims who use these services is still scant under a regime that has traditionally stymied research, or funneled research through government-led research think tanks. Recent attempts to evaluate victim rehabilitation and reintegration services have been met with trepidation. Though not outright resistant to international research, Chinese government officials are quick to use trafficked victims' vulnerability as a justification for limiting transparency over protection and rehabilitation practices. ${ }^{17}$ Thus, while measures to improve services exist, there is still limited transparency about the quality of protection and rehabilitation services.

In early 2007, anti-trafficking stakeholders in China gathered in Ruili City to commemorate the launching of the area's first Border Liaison Office (BLO) to target human trafficking. The BLO is part of a series of bilateral commitments between China and Myanmar including the signing of a Bilateral Memorandum of Understanding (MOU) between the two governments. ${ }^{18}$ Focussed on strengthening information sharing, intelligence exchange, arrest and prosecution of traffickers, and mutual assistance in rescuing and repatriating victims, the border checkpoints are primarily aimed at reducing cross-border trafficking and facilitating the repatriation of victims of trafficking. ${ }^{19}$

\footnotetext{
Fieldnotes 12/2012.

18 The Ruili BLO collaborates with its Myanmar counterpart in Muse, the town on the Myanmar side. While both sides of the China-Myanmar border are worthy of research, this paper focusses primarily on data collected from the China side.

19 UNIAP China, 'First China-Myanmar Border Liaison Offices Meeting on Antitrafficking and Joint Border Visit,' humantrafficking.org: A web resource to combating human trafficking, 31 March 2007, http://www.humantrafficking. org/updates/530; Xinhua, "42 Trafficked Myanmar Citizens Repatriated from Thailand', China Daily, 15 October 2009.
} 
In 2010, the director of the Ruili Criminal Investigations Department reported that a total of 489 Burmese women have been repatriated since the opening of the BLO, and this number is likely to have risen, though no recent reports are available. The formal process of victim repatriation involves sending Burmese women back to their hometowns. However, numerous issues frequently emerge with regard to victims who cannot or do not wish to return home and those who prefer to remain in China with their children. Due to the fact that the BLO's functions are primarily restricted to the border, many emotional and material needs exceed the capacities of the BLO. For instance, the focus only on the physical transfer of victims for the purpose of 'repatriation' means that the BLO does not address needs of victims in destination or source communities. The bilateral processes provide public figures for official rates of repatriation, treating repatriation as a singular event rather than a process. Once again, qualitative insight or assessment into the quality of services provided is lacking. By focussing efforts on policing and patrolling the border, interventions like the BLO ignore systemic sources of risk to trafficking and other social problems in this border region, as we see below.

\section{Drugs and Ethnic Marginalisation}

Emphasising the prosecutorial dimensions of trafficking intervention echoes the narrow focus on criminality in the Chinese government's attitude towards drugs and disease. Framed primarily as problems of social disorder, their solutions are characterised by punitive as opposed to protectionist or development-based interventions. Anti-drug policies and antitrafficking policies are linked through their focus on prosecution. Anti-trafficking interventions are not incorporated into antidrug policies, but build on pre-existing punitive measures that marginalise people.

While opium growth in China began as early as the $18^{\text {th }}$ century, the cross-border opium trade grew during the late 1970s when China sought to engage in trade with Burma. Chinese partnership appealed to Burmese partners because it 
introduced more advanced technical know-how and access to global markets. ${ }^{20}$ Due to its location just above the Golden Triangle, linking opium-producing areas in Vietnam, Laos, Thailand and Myanmar, Ruili was an ideal entry point for heroin distribution through China to other parts of the world. This illicit trade was a consistent staple of the cross-border economy until the economic reform era in the 1980s when sweeping attempts to formalise economic markets brought about drastic changes in the drug producing areas of Yunnan. On demand from the central government, poppy fields in Yunnan were systematically burnt to show intolerance for drug trade, and this moved much of the drug production to the Myanmar side of the border. ${ }^{21}$

Lacking economic opportunities for income generation, many ethnic minority persons in Yunnan turned to the illegal heroin trade and were often paid in the heroin they trafficked. Concurrently, a public health crisis developed. In 1989, Ruili was documented as the city where the first cases of HIV were discovered in China, when a study found that 146 injecting drug users (IDUs) in Ruili were HIV positive. ${ }^{22}$ In the past 20 years, Dehong Prefecture (which includes Ruili City) has consistently ranked first in rates of HIV infection and AIDSrelated deaths in Yunnan Province. By the early 1990s, rates of HIV infection were highest in Ruili and three other surrounding counties. By the end of the decade, HIV had spread across the whole of Yunnan Province with severely high concentrations of 50-80 per cent in communities of IDUs. ${ }^{23}$

${ }^{20} \mathrm{~K}$ Chin, The Golden Triangle: Inside Southeast Asia's drug trade, Cornell University Press, NY, 2009, p. 83.

21 G Fu, 'Shi Shen de Shequ Jiqi Zhongjian Zhidao-Ruili Shi Jingpo Zu Dupin he Aizibing Weihai de Chengyin Jiqi Duice', Central University for Nationalities, Doctoral Dissertation, 2006.

22 Z Wu, J Zhang and Z Li, 'Risk Factors for Initiation of Drug Use among Young Males in Longchuan, Yunnan', Chinese Journal of Epidemiology, vol. 20, issue 1, 1999, pp.15-18.

23 G Jing and N Renwick, 'China's Fight against HIV/AIDS', Journal of Contemporary China, vol. 17, issue 54, 2008, pp. 85-106. 
In the village of Banpai where this study took place, the Chinese Center for Disease Control (CDC) reported an 80 per cent HIV infection rate amongst Jingpo men who were former IDUs. In the late 1990s, the CDC entered villages in Ruili and mandatorily tested men who had admitted to being current or former IDUs. However, children, wives and sexual partners of IDUs were frequently not tested, nor were they given education about how to reduce transmission because they did not fall into the 'high risk group' of drug users. ${ }^{24}$ Two years ago, at the closing exhibition of a summer art programme in Banpai, the mother of one of the participants pulled my Jingpo colleague aside and asked about the health of her eight-year-old daughter: 'Do you think that my daughter might have AIDS? They diagnosed her father many years ago, but we never got tested.' ${ }^{25}$ On a separate occasion, this mother admitted that she felt 'shy' but felt compelled to ask: 'Do condoms really prevent AIDS? I'm not sure if it's ok to be together with my husband.' ${ }^{26}$ Nearly a decade after her husband was initially diagnosed as HIV positive, she still lacked basic information about health, transmission, and safe practices for herself and her daughter because education has not been earmarked as a priority for intervention.

While protection and educational campaigns remain absent, what is abundantly clear to residents are messages posted at the entrance to the village warning 'Avoid drugs, AIDS and death'. A plaque put up by the county-level civil affairs bureau labels Banpai a 'Pilot project site for elimination of drug use and AIDS'. For residents, these signs and placards mark the uncomfortable presence of drugs and disease in Banpai. As previously mentioned, many women in Banpai have not been equipped with knowledge of harm reduction, and understand HIV infection primarily through fear and stigma campaigns. Further, those diagnosed with HIV are not given formal social or community support, and neither are their families. Ah Xian's mother, mentioned in the introductory vignette, had already begun taking trips back to her home village after her husband

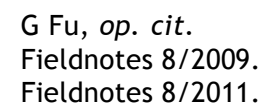


was diagnosed with HIV in 1998. In an interview after her husband's death, I asked her why she travels back so often and she responded: 'It was not meaningful to stay here. After he [her husband] got sick, he would just wake up and drink, and then he would throw bottles and things around the house. He never helped with any of the fieldwork. It wasn't just that he was sick, but that he drank too much and was scary. ${ }^{27}$ Lacking positive forms of community support, Ah Xian's father turned to alcohol and violence to deal with what he considered a death sentence, and her mother sought to distance herself from Banpai.

In other parts of China, Hildebrandt documents that the Chinese Center for Disease Control officials often associate HIV/AIDS as a problem of 'out groups'-inclusive of both sexual and ethnic minorities. ${ }^{28}$ Other reports have documented discriminatory practices including mandatory testing of 'high risk' groups, mandatory drug rehabilitation sentencing, and non-consensual disclosures of infected status. ${ }^{29}$ The public campaigns do little to target the root causes of HIV/AIDS risk, instead suggesting that entire populations of ethnic minorities are 'high risk' groups and thus effectively stigmatising them. ${ }^{30}$

\section{Forced Marriage as Human Trafficking of Jingpo Women}

While managing the problems of drugs and disease have been a priority since the $1980 \mathrm{~s}$, the issues of forced marriage and

\footnotetext{
Interview conducted in 7/2011.

T Hildebrandt, Social Organizations and the Authoritarian State in China, Cambridge University Press, 2013.

29 Human Rights Watch, 'Locked Doors: The human rights of people living with HIV/ AIDS in China', 3 September 2003, C1507, retrieved 2 May 2013, http:// www.refworld.org/docid/3fe478e27.html; Chinese State Council, Methods for Forced Detoxification [Qiangzhi jiedu banfa], 12 January 1995, article 6; S Hyde, op. cit.

30 See: S Joag, 'Infected Objects: The criminalization of infected bodies through the construction of the materiality of HIV/AIDS stigma', Master's thesis for Program in Crime Social Control and Globalization, London School of Economics, 2009; G Fu, op. cit.
} 
marriage migration, though longstanding practices in the area, have received more recent attention in light of the escalating Chinese attention to human trafficking. On the China-Myanmar border, forced marriage is a problem both for people from Ruili and from the Burmese communities over the border, as well as for numerous stateless communities that live in between. While existing research discusses repatriated victims of forced marriage from Myanmar to China, ${ }^{31}$ less is known about internal cases of forced marriage from the Chinese side of the border to other parts of China. Forced marriages hinge on a complex web of social and demographic changes in China, and very little is done by government anti-trafficking campaigns to address such heavily compromised forms of marriage.

Contemporary accounts of forced marriage within China draw on explanations of the long-standing practice of bride selling in China, particularly in ethnic minority communities, for reasons ranging from poverty, unequal gender balance (because of China's one-child policy) to deep-seated cultural practice. ${ }^{32}$ However, the complex situation of marriage and migration in Ruili reveals a more complex terrain of intersecting issues. Recently, marriage has been understood as an economic strategy within a particularly limited economy. As the marriage market grows, marriage brokers and recruiters have capitalised on the potential to exploit these marriage practices, increasing the risks in migration that female migrants face.

For instance, Gun Tang, a Jingpo woman born in Banpai, was recruited by a fellow Jingpo woman for marriage into a Han family in Shandong Province. Gun Tang initially agreed to this marriage for a one-time fee of 15,000 RMB (2,400 USD), in order to pay for her mother's debts following the sudden

\footnotetext{
Palaung Women's Organization, Stolen Lives: Human trafficking from Palaung areas of Burma to China, Palaung Women's Organization, 2011.

32 E Croll and E J Croll, The Politics of Marriage in Contemporary China, Cambridge University Press, 1981; L B Duong, D Belanger, and K T Hong, 'Transnational Migration, Marriage and Trafficking at the China-Vietnam Border' in I Attané and C Guilmoto ( eds.), Watering the Neighbour's Garden: The growing demographic female deficit in Asia, CICRED, 2007.
} 
death of her father. However, once Gun Tang arrived in Shandong, the recruiter received the money from her new husband's family and left abruptly without paying the fee owed to Gun Tang. Gun Tang was not permitted to contact her mother, and was told that she could not leave this family residing in a remote and isolated part of Shandong until she had a child. She did not speak Mandarin and expressed feeling socially isolated. She did not try to leave because she was unfamiliar with the area and distrustful of local Han police and government. Since she did not possess a Chinese identity card, she believed that she would be arrested for being an undocumented migrant. After two years of living together, Gun Tang said that a love bond developed between her and her husband, and she succeeded in convincing her husband to let her make a trip to Ruili. Once in Ruili, she was able to convince her husband to move to Ruili with her, and eventually he agreed. His decision, she noted, reflected how rural areas across China have limited opportunities for upward mobility and that living in a rural village in Yunnan Province was not so different to her husband.

At the end of our interview, Gun Tang shared that there are several Jingpo women in Shandong Province who were forcibly married and still have unpaid debts. Yet, despite being lied to, cheated, and duped in various forms, they choose not to return to Ruili. Gun Tang said, 'Many have kids now, and after living there so long, they just want to stay, because they are really not sure what to come back to.' In particular, she was referencing the fact that Jingpo women have become mistrustful of Jingpo men; in addition to the lack of potential marriage partners, they share a sense of futility in returning to a community affected by drugs, disease and frequent death. Gun Tang's accounts portray a complex story of forced marriage that by its definitional parameters would be classified as a case of human trafficking under both Chinese and international legal frameworks. Its complexity unfolds the challenges in Ruili's border identity, where Gun Tang's marginalised ethnic identity made her both vulnerable to trafficking and unable to seek formal assistance in Shandong. The nexus of these forms of marginality reveal conflicting 
and contemporaneous moments of agency, decision-making and risk-taking that many migrants from this area face.

As has been argued by feminist scholars in other contexts, the focus on women and children as true victims leads to a dangerously dichotomous portrayal of men as criminals and perpetrators. ${ }^{33}$ In China, human trafficking and drug related policies can be understood through the lens of carceral protectionism, for how they employ punishment and policing in order to pursue the alleged goals of social protection. What has evolved to be a gendered form of policing has consequences in Dehong, where the criminalisation of heroin trade has already increased rates of incarceration for ethnic minority men. These dichotomous identities of victim and criminal, typically organised around gender, ${ }^{34}$ are harmful in China's ethnic and geographic borderland areas, where for the Jingpo in particular, 1) men are disproportionately affected by HIV/AIDS and 2) both women and men are disenfranchised by state policies that favour urban and Han majority citizens. Furthermore, this is complicated by the fact that many women and men in this area do not have citizenship, and thus do not fit eligibility criteria for social protection.

\section{Conclusion}

The social problems that exist at the nexus between borders, marginality and human rights converge for Jingpo communities in Ruili through lack of citizenship rights, uneven access to resources, the problematic ramifications of policing drugs and disease, as well as the focus on criminalisation and prosecution when addressing human trafficking. In light of the history of drugs, disease, and their policing, the recent attention to

33 See: E Bernstein, 'Militarized Humanitarianism Meets Carceral Feminism: The politics of sex, rights, and freedom in contemporary antitrafficking campaigns', Signs, vol. 36, no. 1, 2010, pp. 45-71; J Musto, 'Carceral Protectionism and Multi-Professional Anti-Trafficking Human Rights Work in the Netherlands', International Feminist Journal of Politics, vol. 12, issue 3-4, 2010, pp. 381400; W Chapkis, op. cit.

34 Significantly, gender is the primary means of delineating trafficking victim status, as indicated in Chinese Anti-Trafficking National Plan of Action, which defines trafficking as a problem exclusively concerning women and children. 
human trafficking in China generally, and Ruili specifically, complicates the discursive and material politics of gender and citizenship for ethnic minorities in China. Government fear and stigma campaigns increase risks for women because they invoke mistrust of ethnic, social and family fabrics of support. Women are more inclined to seek migration, even dangerous migration, as an option for upward mobility.

Given the state of cultural decay in Jingpo communities, cultural interventions are needed, like those pursued by Peters (2012) and Fu (2006) which target de-stigmatisation to increase moral support within the community. These existing cultural interventions aim to rebuild communities through decreasing cultural stigma and strengthening sources of ethnic community pride. This research points to the need for further attention to community resources as 'informal' modes of human trafficking assistance. While Gun Tang was not able to access any formal resources-through the government and NGOs-she resolved her situation through community support and self-reliance, which often lie outside the purview of what is considered human trafficking assistance. ${ }^{35}$

Prioritising human trafficking as a problem of women and children as true victims obfuscates general rights issues for men and women and ethnic minorities. Rather than focus on women and children as true victims through legal and policy frameworks, and the lens through which existing antitrafficking campaigns understand risk, we should continue asking how Jingpo women and men experience the host of challenges in this area. The preliminary findings of this research suggest that the problems of human trafficking and HIV/AIDS, though they are commonly regarded as distinct in human rights and public health discourses respectively, must be understood through an intersectional framework that is attuned to the needs of community development. Finally, the

35 H Peters, 'Best Practice for Reaching the Unreached: Ethnic minorities and HIV prevention', Regional Unit for Culture in Asia and the Pacific, UNESCO Bangkok, 2012; A Brunovskis and R Surtees, Leaving the Past Behind: When victims of trafficking decline assistance, Fafo, Norway, 2007; G Fu, op. cit. 
findings here warn us that the global shift towards regarding human trafficking as the most 'heinous' and 'monstrous' phenomenon of the current age obscures ongoing issues of risk and cultural stigma for ethnic minority peoples globally. ${ }^{36}$ The recent arrival of the BLO (policing borders as opposed to protecting communities) sheds light on the excitement and newness and exceptionalism of human trafficking as a buzzword. This has obscured the links between trafficking in persons and other risks people face due to multiple forms of marginalisation.

Elena Shih is a doctoral candidate in the Department of Sociology at UCLA, where she is a Ford Foundation Dissertation Fellow and an American Sociological Association Minority Fellow. Her dissertation research compares faith based and secular factions of the transnational movement to combat human trafficking in China and Thailand. In 2004, she was a Fulbright Fellow at the Peking University Center for Women's Law Studies and Legal Aid. During her time in China, she also co-founded a community arts programme that provides a no-cost arts education to ethnic minority youth living on the China-Burma border (www.theborderartsproject.org). This research was sponsored by fieldwork grants from the UC Global Health Institute, UCLA Asia Institute, and UCLA Center for Chinese Studies.

Email: elenashih@ucla.edu

36 'New Action to Eradicate the 'Heinous Crime' of Human Trafficking,' The Courier, 30 July 2013, http://www.thecourier.co.uk/news/scotland/new-action-toeradicate-the-heinous-crime-of-human-trafficking-1.116101; E Skinner, A Crime so Monstrous: Face-to-face with modern-day slavery, Free Press, 2009. 
DOI: 10.14197/atr.20121327 